\title{
Evaluation of the biomedical properties of hydroxyapatite obtained from bone waste
}

\author{
Agnieszka Sobczak, Anna Kida, Zygmunt Kowalski, Zbigniew Wzorek \\ Cracow University of Technology, Institute of Inorganic Chemistry and Technology, ul. Warszawska 24, 31-155 Kraków, \\ Poland, e-mail: asobczak@chemia.pk.edu.pl
}

\begin{abstract}
The method of obtaining hydroxyapatite by thermal treatment of deproteinised and defatted bone pulp called bone sludge was presented. The products of the calcining process were characterized with X-ray diffraction (XRD) and Fourier transformed infrared spectroscopy (FT-IR). The calcium content was determined with titration, whereas the contents of total phosphorus - with a spectrophotomertric method. X-ray investigations confirmed that hydroxyapatite was the main component of the calcining products in the calcining process. The FT-IR spectra confirmed that all organic substances were removed during the calcining process. On the basis of the research into physiological liquids the propensity to resorption of hydroxyapatite bioceramic was evaluated.
\end{abstract}

Keywords: bone sludge, hydroxyapatite, calcining, incubation, SBF, Ringer liquid.

\section{INTRODUCTION}

Hydroxyapatite (HAp) is the main mineral component of human and animal bones ${ }^{1}$. In this respect we have taken tests of processing bone waste and products applied in medicine as biomaterials. For the sake of the properties like bioresorption, biocompatibility, osteoconductivity, it could become a very good material in bone surgery. In addition, many research results indicated that this material could be applied in stomatology ${ }^{2}$. Hydroxyapatite biomaterials applied in bone surgery included dense and porous materials, coating materials and composites in which the second phase could be metals, carbon materials and also polymers, both biodegradable and bio-stable. The additional advantages of hydroxyapatite ceramics are the following: high chemical purity, invariability during sterilization, good adaptation to an organism. The unsatisfactory mechanical properties are the disadvantage of this material and in this respect the range of HAp applications is limited ${ }^{3}$. Hydroxyapatite bioceramic could be classified to a group of non-toxic, non-carcinogenic and biologically active materials. There is a lack of features of rejection by a recipient organism and even proceed to compact connection between the material and tissue ${ }^{3,4}$. HAp has an effect on intensive bone growth and it provides biological stability of the reconstructed tissues. The hydroxyapatite material demonstrates the "conducting" properties of a growing bone tissue. HAp bioceramic simulates the microstructure of a natural bone and provides a scaffold, which facilitates an overgrowth of an implant ${ }^{2-5}$.

\section{EXPERIMENTAL PART}

Bone sludge and preliminary heat treatment in rotary kiln

Bone waste from meat industry applied in our research was deproteinised and defatted bone pulp called bone sludge that was formed as waste in deproteinisation process of pork bones, in which a protein hydrolysate was the main product. Hydroxyapatite was received in the calcining process in two stages. In the first stage the material was calcined at the temperature of $600^{\circ} \mathrm{C}$ in a rotary kiln with gaseous heating. In the next stage the unified material from the first stage was calcined at five different temperatures $(650,700,800,900$ and $950^{\circ} \mathrm{C}$ ) and kept in the maximum temperature for 2.0 hours in a chamber kiln with electric heating in air atmosphere. The intermediate product after calcining in the rotary kiln (basic material) was heterogeneity. The shape of individual particles was irregular and the size ranged from $1 \mathrm{~mm}$ to tens of $\mathrm{mm}$. The basic material had a colour from dark grey to black because of organic substances, which were not combusted during thermal processing in the rotary kiln. The material from the first stage of the process was ground and further calcined and sieve fraction below $0.150 \mathrm{~mm}$ was used for research

The phase composition was determined with the X-Ray method on Philips X'Pert diffractometer equipped with PW 1752/00 graphite monochromator. The X-Ray analysis showed that the only crystalline phase in bone sludge is hydroxyapatite (Figure 1).

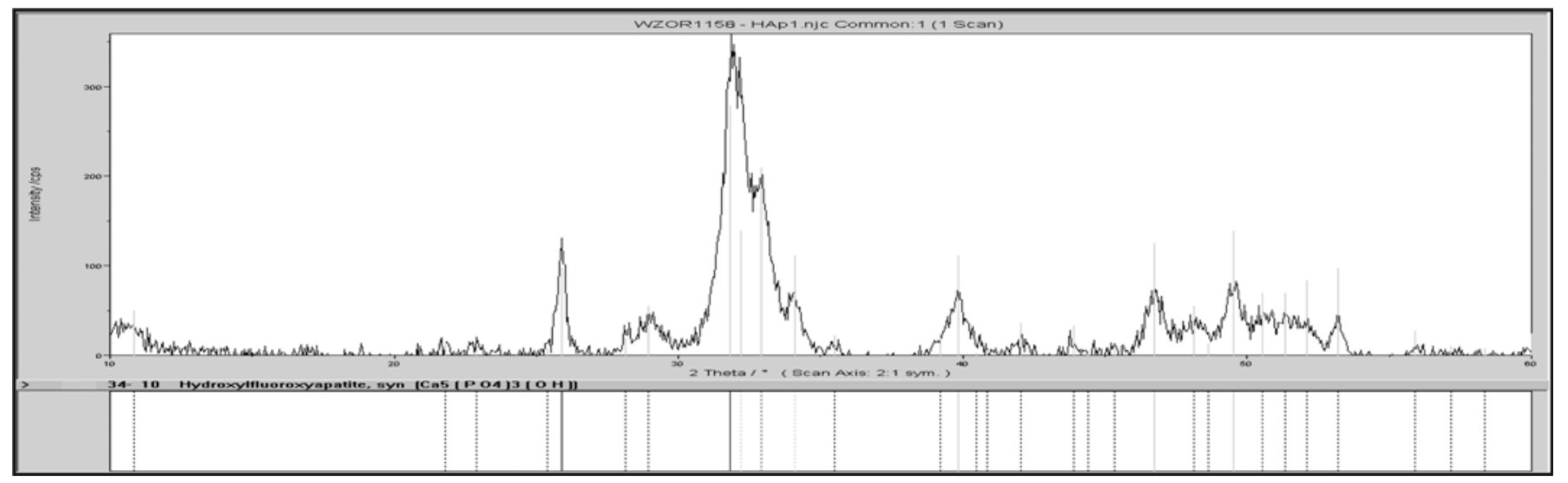

Figure 1. The X-ray diagram of the ashes received in a rotary kiln at $600^{\circ} \mathrm{C}$ 


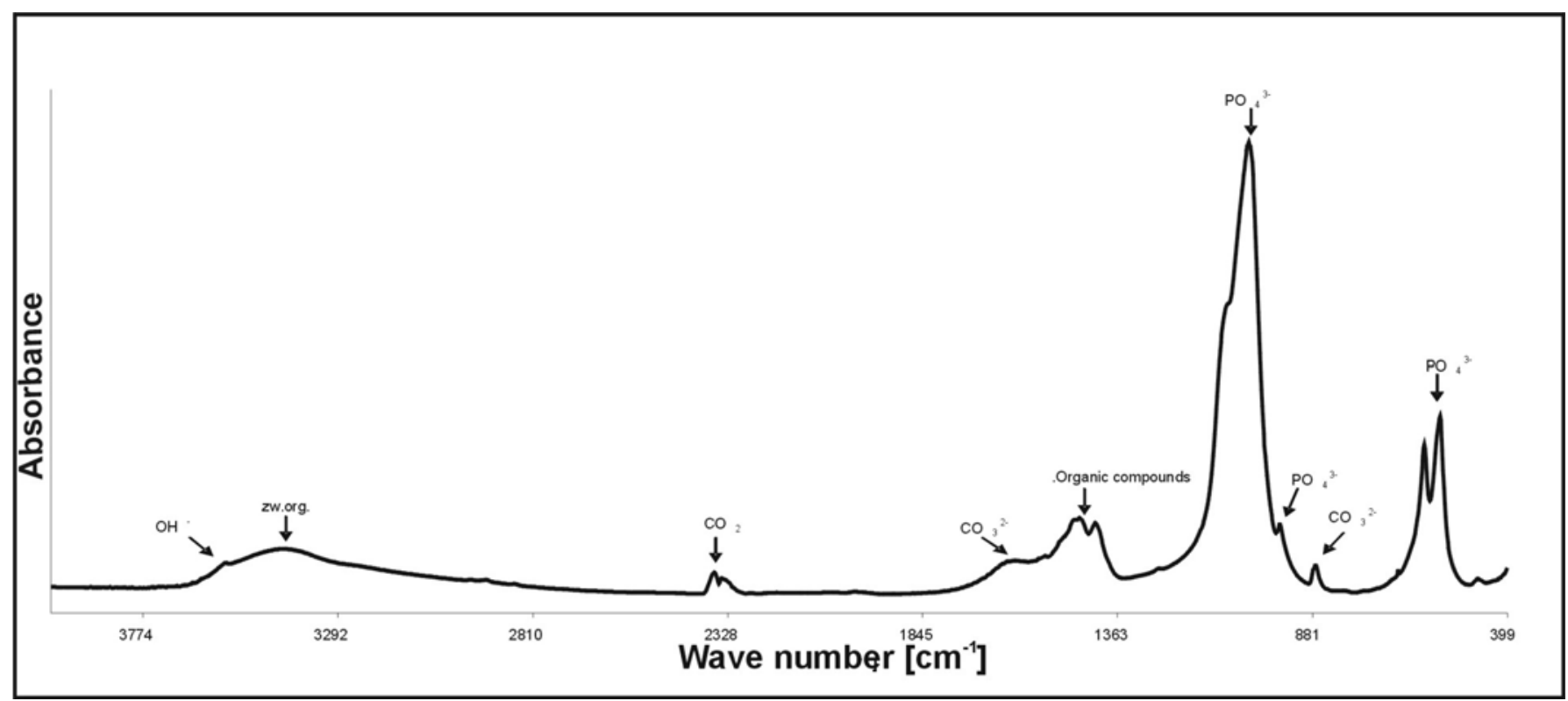

Figure 2. The infrared spectrum of basic material from preliminary calcining

The infrared investigations FT-IR were realized with the spectrophotometer Scimitar Series FTS 2000 Digilab in the range of middle infrared $400-4000 \mathrm{~cm}^{-1}$. A $0.0007 \mathrm{~g}$ sample was pressed with $0.2000 \mathrm{~g}$ of $\mathrm{KBr}$. The number of scans 16 and resolution $4 \mathrm{~cm}^{-1}$ characterized these measurements.

Absorption bands were ascribed to particular bonds according to ${ }^{6-8}$. The most intensive band at $1034 \mathrm{~cm}^{-1}$ corresponded to asymmetric stretch vibrations of $\mathrm{P}-\mathrm{O}$ bond, whereas the maximum of absorption at wave numbers 964 $\mathrm{cm}^{-1}$ came from the symmetric vibration of $\mathrm{P}-\mathrm{O}$ bond. The vibrations of O-P-O bonds were assigned to the absorption bands within wave numbers range of $604-563 \mathrm{~cm}^{-1}$. The low intensity bands at 1457 and $881 \mathrm{~cm}^{-1}$, which were observed for the material received in the preliminary calcining process, could correspond to the stretching vibrations of $\mathrm{CO}_{3}{ }^{2-}$. The band in the high wave number range resulted from the vibration of $\mathrm{O}-\mathrm{H}$ bonds. The broad bands at wave numbers 1400 and $3300 \mathrm{~cm}^{-1}$ corresponded to the vibrations of organic compounds. The band in the high wave number range $\left(3427 \mathrm{~cm}^{-1}\right)$ resulted from the vibration of O-H bonds.

\section{Calcining process in stationary kiln}

In the second stage the unified material was calcined at $650^{\circ} \mathrm{C}, 700^{\circ} \mathrm{C}, 800^{\circ} \mathrm{C}, 900^{\circ} \mathrm{C}$ and $950^{\circ} \mathrm{C}$ and kept at the maximum temperature for 2.0 hours. The calcining process was realized in a chamber kiln with electric heating in air atmosphere. The phase composition was analyzed with the X-ray method. Hydroxyapatite was the only crystalline phase observed in all the calcining products. However, the XRD analysis showed that a crystallization degree of the product increased with the calcining temperature.

Bands corresponding to the vibrations of $\mathrm{C}-\mathrm{H}$ and $\mathrm{C}-\mathrm{C}$ bonds present in organic compounds were absent from these spectra. It confirmed that the whole organic material was removed. It was possible to notice a decrease in the intensity of bands corresponding to a carbonate group, which resulted from a partial decomposition of that group during the calcining process.

Phosphorus and calcium content is presented in Figure 4. The phosphorus content was determined on UV-VIS Marcel Media spectrophotometer with a diffraction-photometric method according to the PN-88/C-87015 after the former sample mineralization with concentrated hydrochloric and

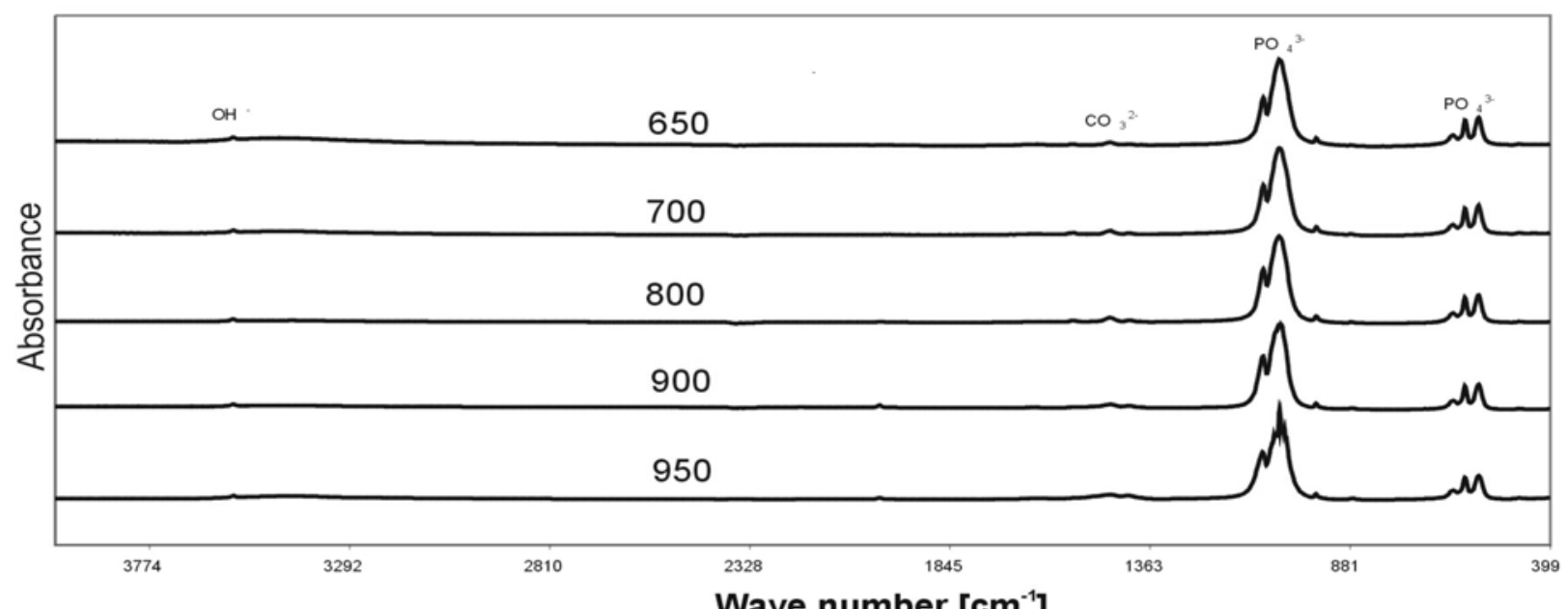

Figure 3. The infrared hydroxyapatite spectra obtained at different temperatures $650-950^{\circ} \mathrm{C}$ 


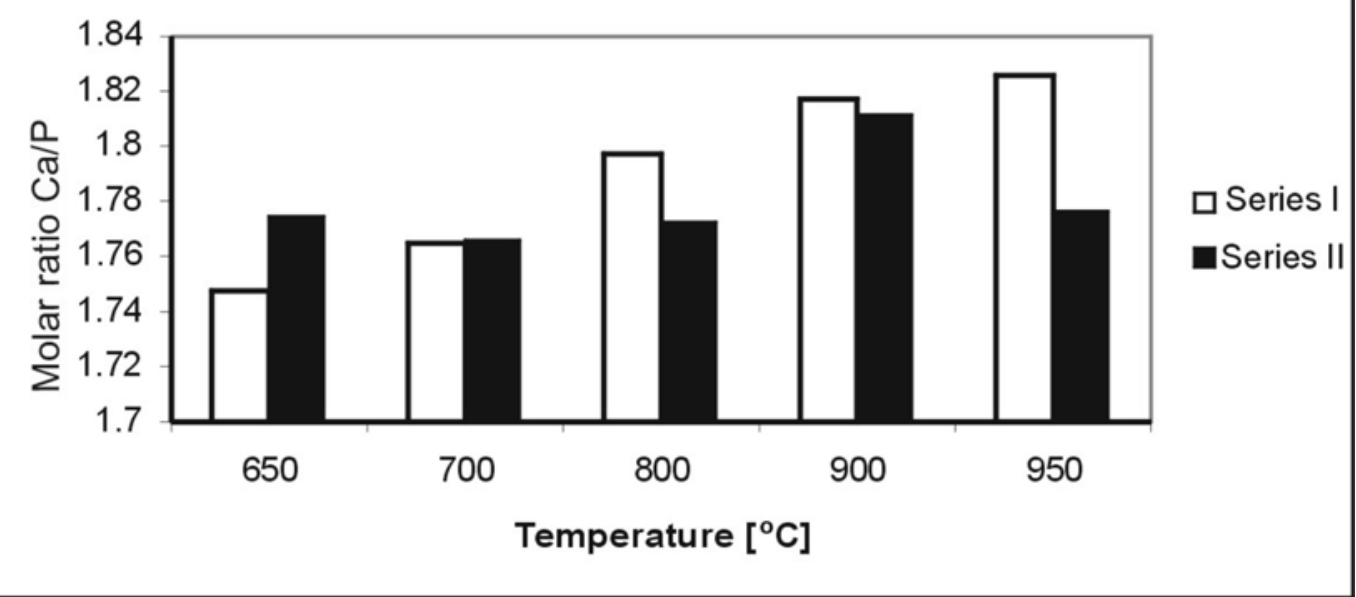

Figure 4. The molar ratio $\mathrm{Ca} / \mathrm{P}$ of hydroxyapatite obtained at different temperatures

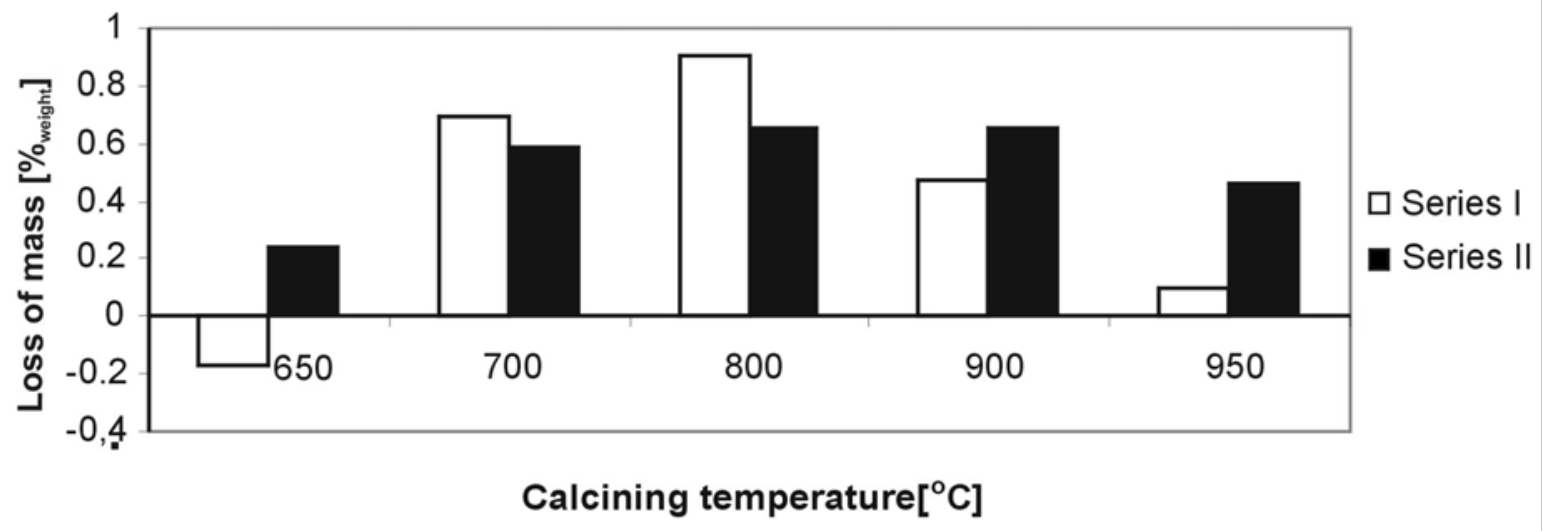

Figure 5. A diagram of mass changes of HA samples incubated in Ringer fluid

nitric acids. Calcium was appointed with the titration method according to the PN-R-64750:1993 in the presence of an indicator - calcein and thymolphthalein. The content of phosphorus was approximately $17.5 \% \%_{\text {weight }}$, whereas the content of calcium was in the range from $39.48 \%_{\text {weight }}$ to $41.72 \%$ weight. The analyses confirmed that the content of phosphorus and calcium in the products increased with the calcining temperature. The molar ratio of calcium to phosphorus for the samples after calcining at different temperatures changed and corresponded to the molar ratio $\mathrm{Ca} / \mathrm{P}$ of nonstechiometric hydroxyapatite. The tendency of the molar ratio $\mathrm{Ca} / \mathrm{P}$ to increase with the calcining temperature was observed, especially for the first series of the measurement.

\section{Investigation of physiological fluids}

In our tests Ringer solution and SBF were applied. Ringer liquid is a type of physiological and isotonic fluid in comparison with body fluid, i.e. the water solution of chlorides: sodium, potassium and calcium. SBF - Simulated Body Fluid - has a chemical composition similar to that of the plasma of human blood. It has an application in vitro investigations of materials used in implantology. SBF is especially useful in the evaluation of the activity of ceramic biomaterials and estimation of chemical durability.

Samples in cylinder shapes were obtained with the use of hydraulic press (weighed amount of $1.1 \mathrm{~g}$ ). Then the samples were sintered in a chamber kiln with electric heating in air atmosphere at $900^{\circ} \mathrm{C}$ and the material was kept at this tem- perature for 2.0 hours. The samples were next put under the conditions simulating an internal environment of a human body. Incubation was realized for 45 days in three kinds of fluids: SBF, Ringer fluid and distilled water. Ceramic cylinders were put into plastic containers, five samples in each container, and $40 \mathrm{ml}$ of an appropriate physiological liquid was poured in. After 45 days the samples were dried to constant mass and analyzed. An average of five measurements was given as the final result.

The change of weight of the samples incubated in SBF indicated the loss of weight for all the materials independent of the calcining temperature. An interpretation of this phenomenon was not unequivocal and required additional tests. It is possible that the proportion between the liquid volume and a specific surface was not proper. Instead of an increment of mass, which resulted from growing hydroxyapatite on a sample surface, we observed an inverse effect, i.e. the degradation of hydroxyapatite surface and the release of ions into the SBF solution.

Ceramic cylinders immersed in the Ringer fluid showed an insignificant tendency to mass increase due to chlorides precipitation from the solution. A sample obtained at a temperature of $650^{\circ} \mathrm{C}$ was an exception and it confirmed the bioactivity of hydroxyapatite. The loss of weight was the result of mechanical damage of one of the samples and its partial disintegration.

The samples immersed in distilled water showed a tendency to the loss of mass. It could be connected with the 


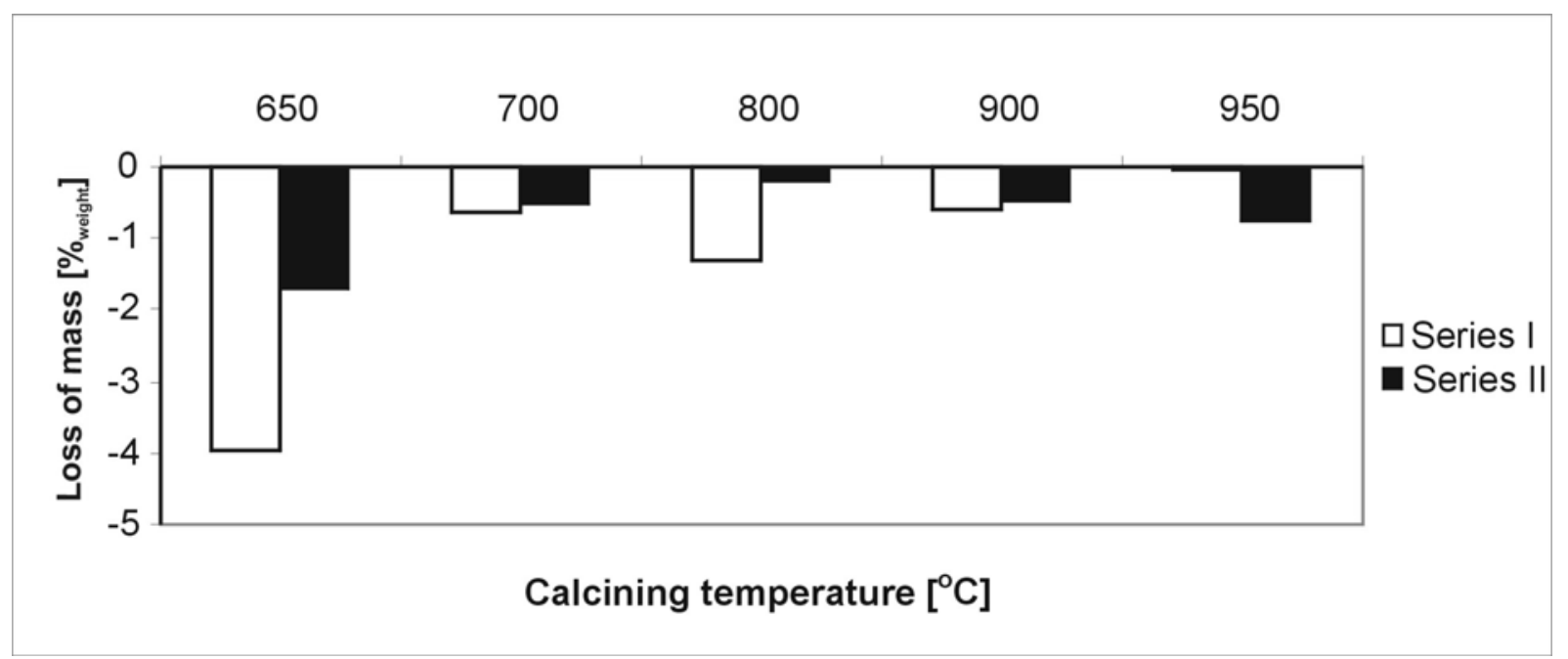

Figure 6. A diagram of mass changes of HA samples immersed in distilled water

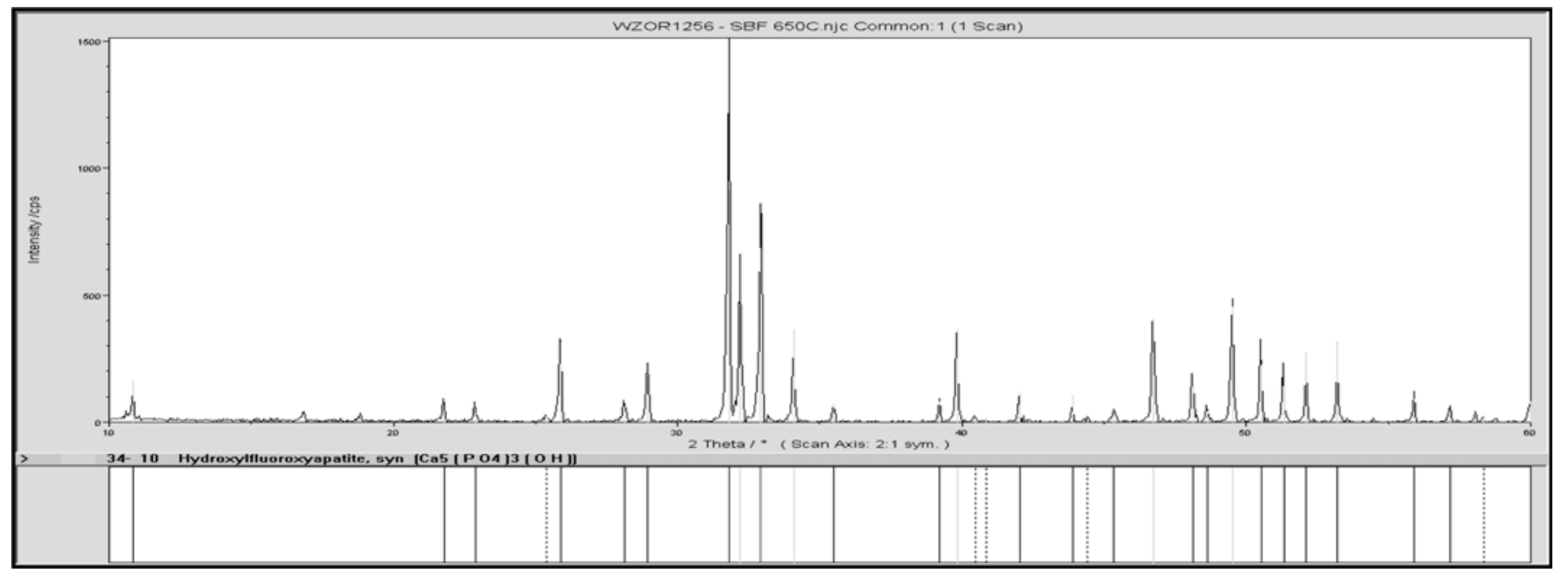

Figure 7. The X-ray diagram of hydroxyapatite obtained at a temperature of $650^{\circ} \mathrm{C}$ immersed in $\mathrm{SBF}$

degradation process and release of hydroxyapatite ions into water. Fractures appeared on a sample surface during incubation.

The X-ray analyses confirmed that hydroxyapatite was the only phase indicated in all the samples immersed in the three different environments. It was found that in all the cases the degradation of hydroxyapatite ceramic structure was not observed. Figure 7 shows a selected X-ray diagram of the material incubated in a simulated body fluid.

Infrared investigations after 45-day incubation in SBF, Ringer fluid and distilled water confirmed that the degradation process did not cause the appearance of additional phases. Intensive bands corresponding to phosphate anions were present in these spectra. We could observe a low intensity band corresponding to carbonate groups and also a band in the high wave number range resulting from the vibration of $\mathrm{O}-\mathrm{H}$ bonds. The FT-IR spectra for the samples incubated in Ringer fluid and distilled water were similar to the spectrum shown in Figure 8.

The content of calcium and phosphorus after 45-day incubation in the three types of environment was analyzed.

The content of total phosphorus after incubation in SBF was evaluated in the range from 18 to $19 \%$. Hydroxyapatite obtained at the temperature of $900^{\circ} \mathrm{C}$ had the lowest content of phosphorus, whereas the samples received at $950^{\circ} \mathrm{C}$ had the largest one. During the 45-day immersion in SBF the content of phosphorus increased in comparison with phosphorus before in vitro tests (Figure 9.).
The content of calcium in hydroxyapatite samples after incubation was at the level from $39.30 \%$ for a sample calcined at a temperature of $650^{\circ} \mathrm{C}$ to $41.02 \%$ for a sample obtained at $950^{\circ} \mathrm{C}$. The comparison of the calcium content before immersion with calcium after in vitro study indicated that the amount of calcium decreased. It could be a result of selective release of calcium ions into the solution.

The analyses confirmed that the quantity of phosphorus in hydroxyapatite samples immersed in the Ringer fluid ranged from 18.90 to $19.23 \%$. The content of phosphorus grew distinctly in comparison with the materials before immersion, like in the case of the simulated body fluid.

The calcium content in the samples incubated in the Ringer liquid amounted from 39.17 to $41.47 \%$. In the case of Ringer liquid the content of calcium also decreased. It could be connected with the transition of calcium ions into the Ringer solution.

The amount of phosphorus in hydroxyapatite samples immersed in distilled water was in the range of 18.80 $20.70 \%$; a very high value obtained for a sample at $700^{\circ} \mathrm{C}$ could be a result of a determination mistake. In other samples the content of phosphorus was at a comparable level. The quantity of phosphorus before immersion was lower in comparison with phosphorus after immersion in distilled water. The growth amounted to $2 \%$.

The large loss of calcium observed for hydroxyapatite obtained at $950^{\circ} \mathrm{C}$ was a result of the degradation process. 


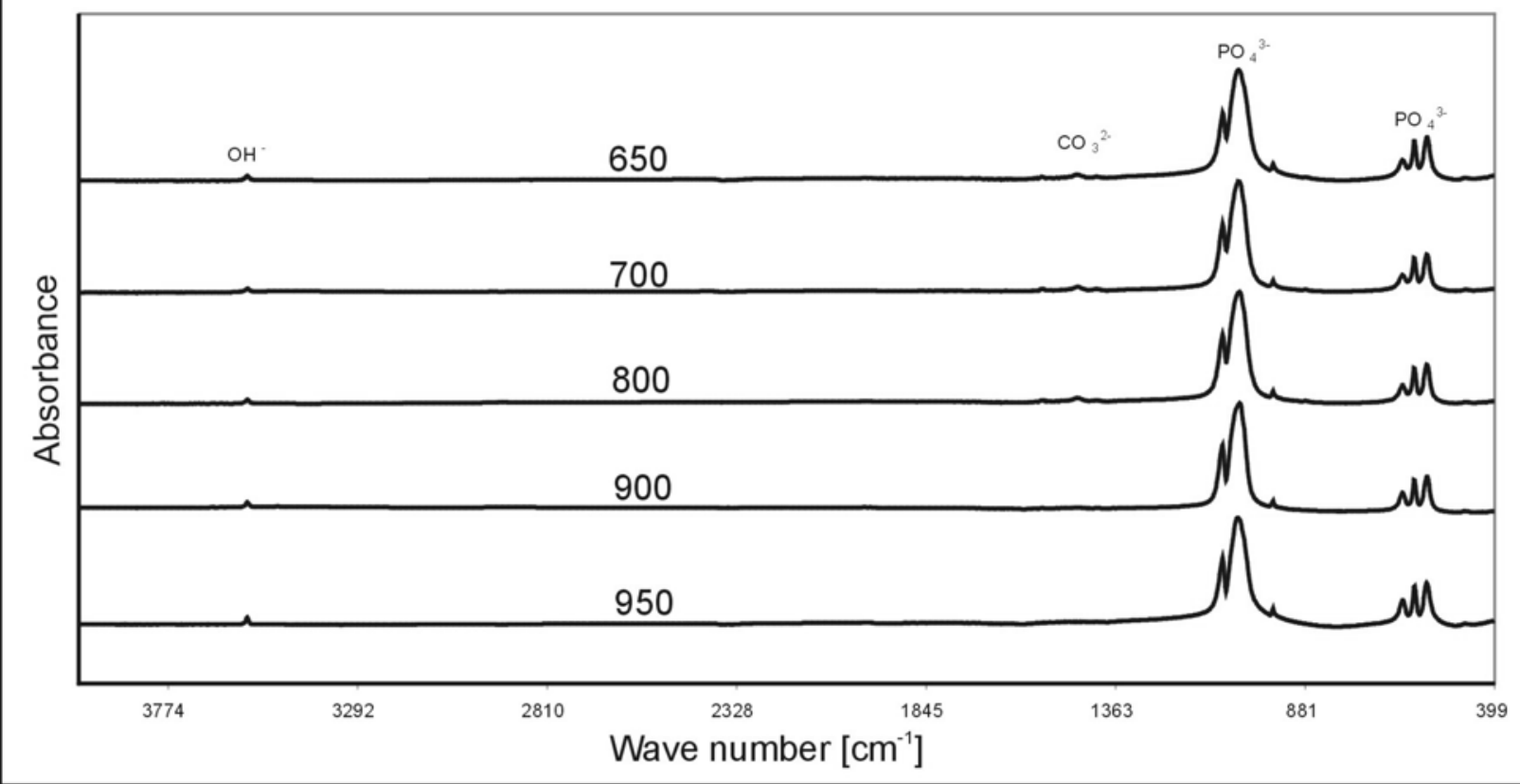

Figure 8. The infrared spectra of HA samples immersed in SBF

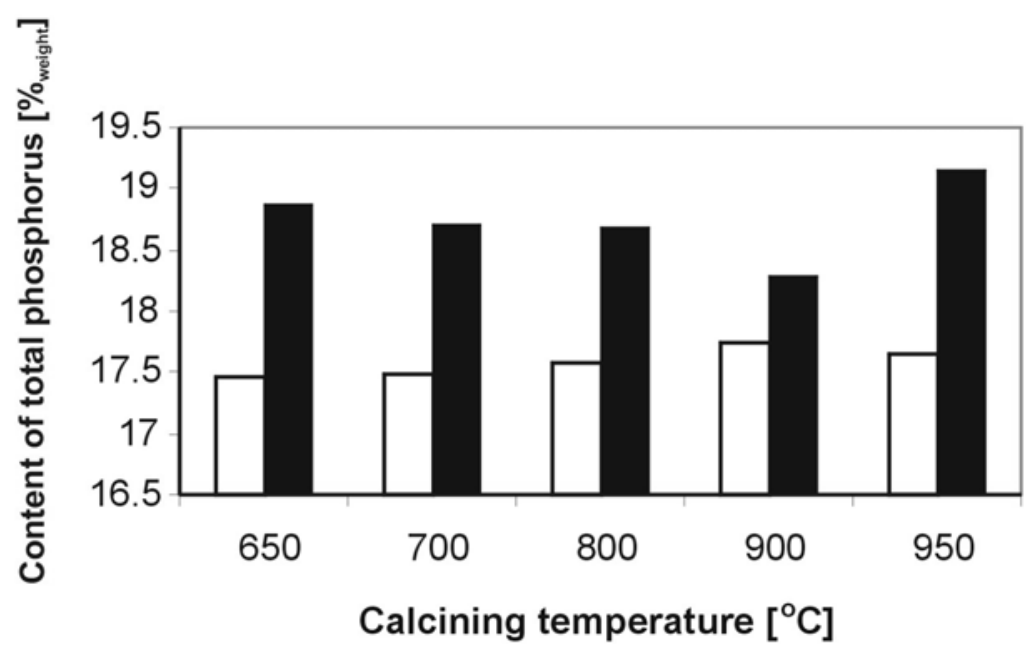

$\square$ Before incubation

After incubation in SBF

Figure 9. A comparison of phosphorus content in HA samples before and after immersion in SBF

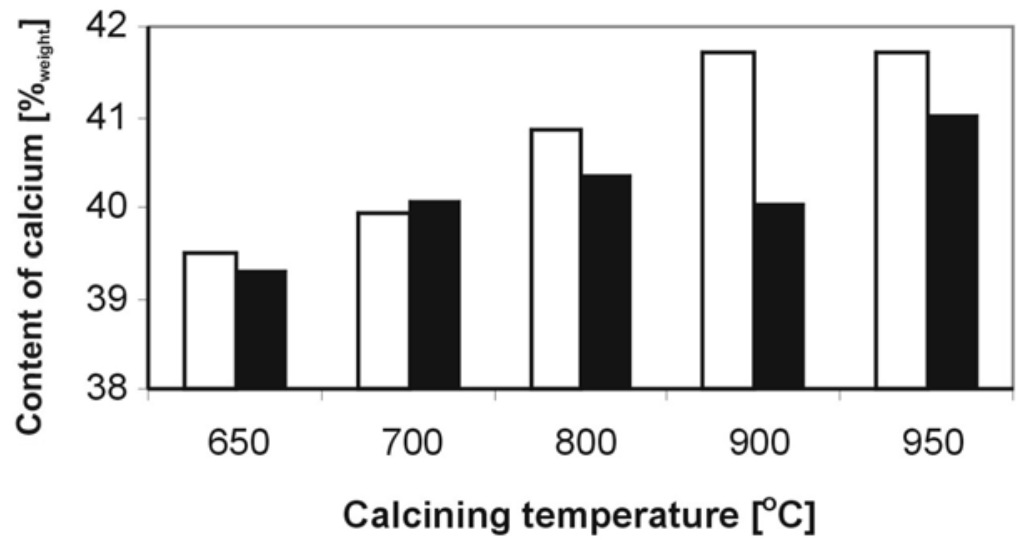

$\square$ Before incubation

- After incubation in SBF 


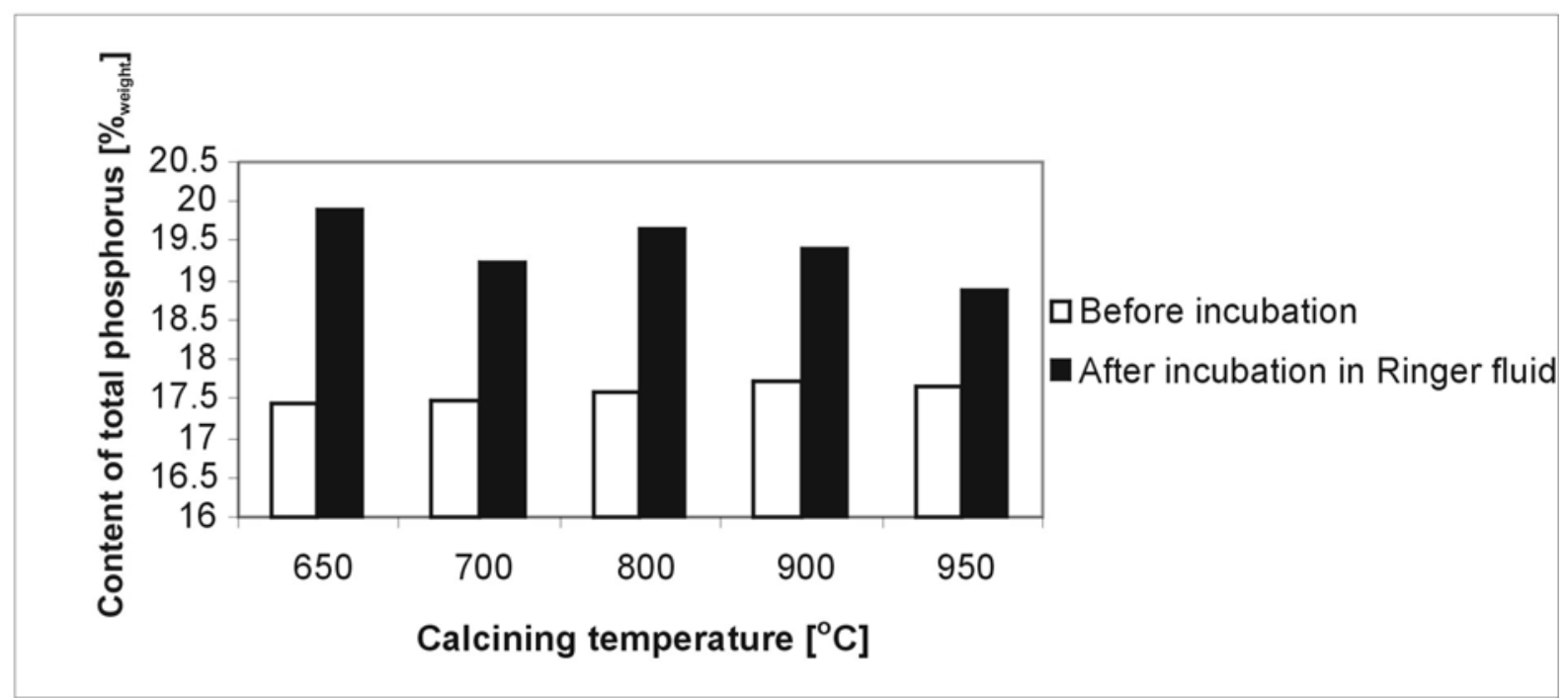

Figure 11. A comparison of phosphorus content in HA samples before and after immersion in Ringer fluid

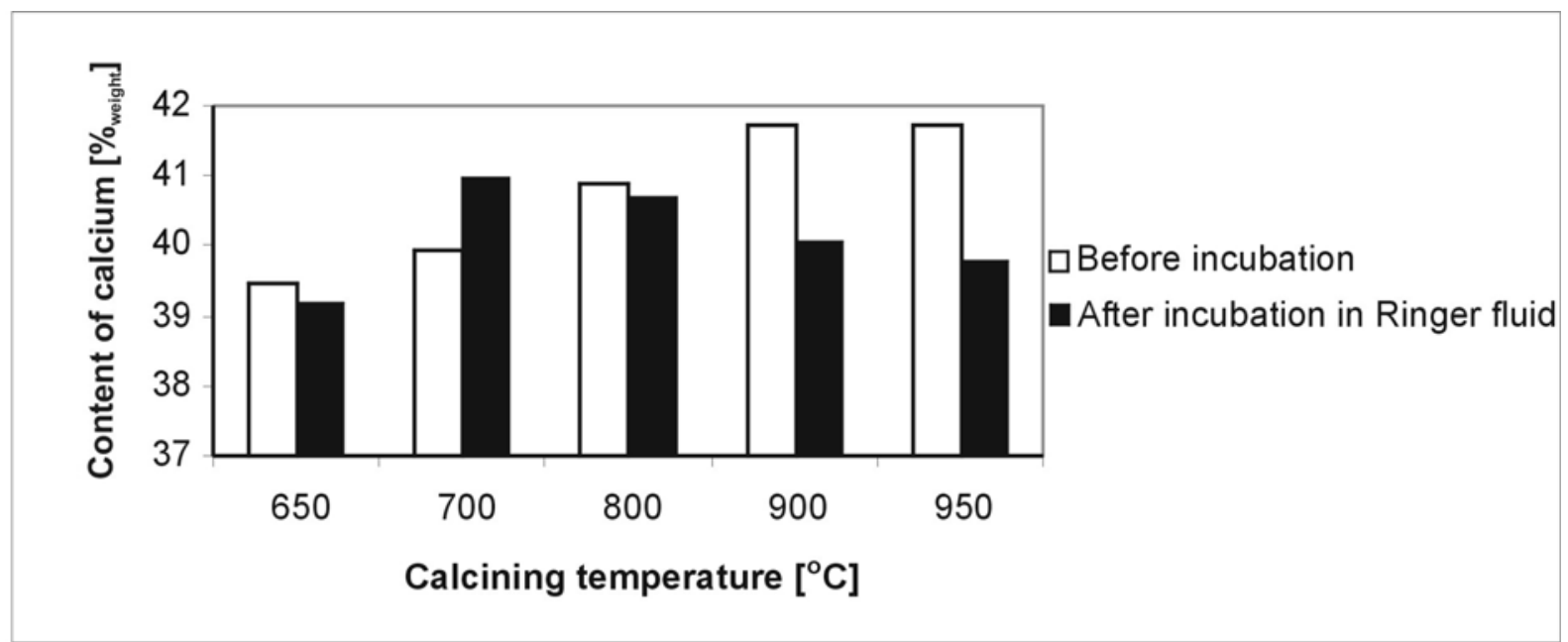

Figure 12.A comparison of calcium content in HA samples before and after immersion in Ringer fluid

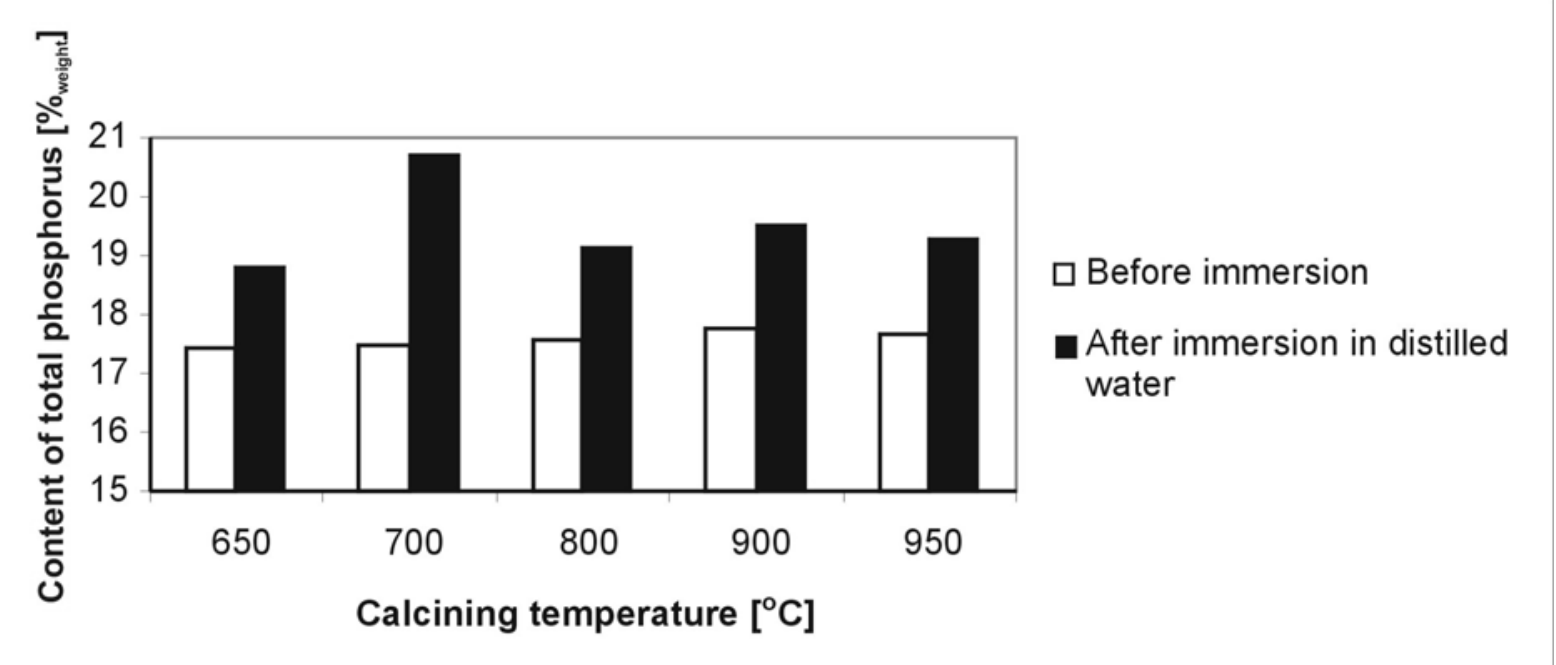

Figure 13.A comparison of phosphorus content in HA samples before and after immersion in distilled water

\section{SUMMARY}

The change of weight of HA samples incubated in SBF indicated the loss of weight for all the materials independent of the calcining temperature. An interpretation of this phenomenon would require additional tests. It is possible that the proportion between the liquid volume and a specific surface was not proper. Instead of an increment of mass that would be growing hydroxyapatite on a sample surface, we observed an inverse effect, i.e. the degradation of hydroxyapatite surface and ions released into the SBF solution.

Hydroxyapatite cylinders immersed in the Ringer liquid showed a tendency to weight increase due to chlorides precipitation from the solution, and showed bioactivity. The 


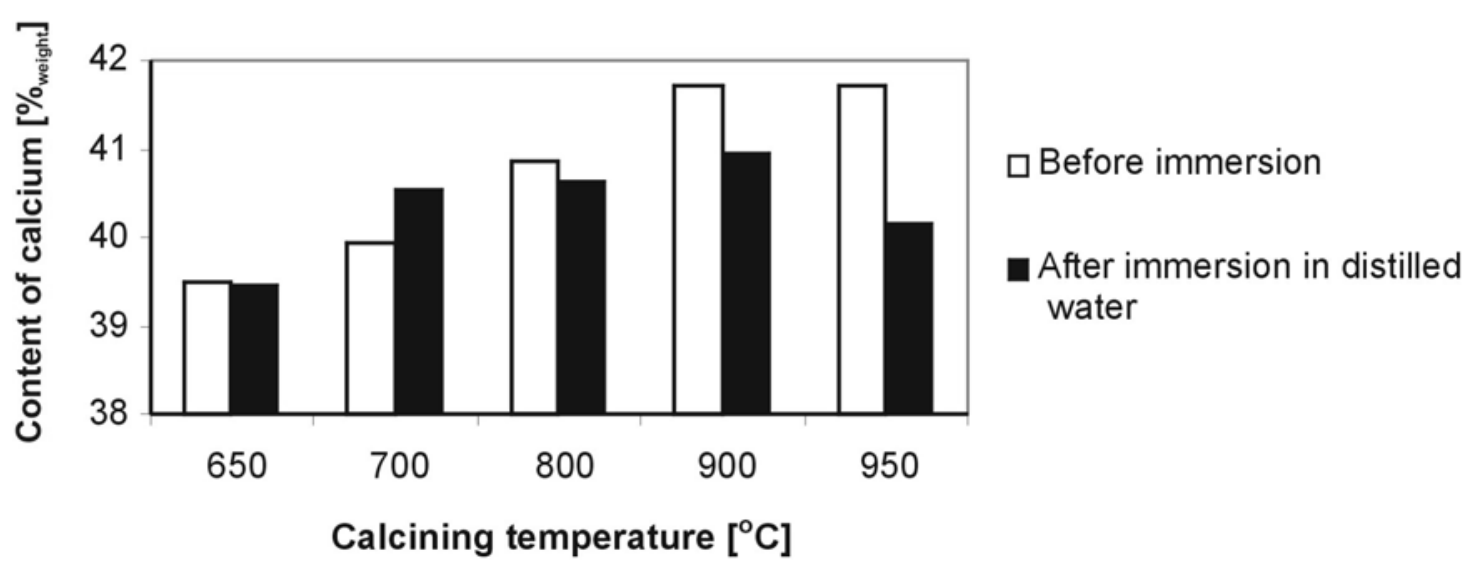

Figure 14. A comparison of calcium content in HA samples before and after immersion in distilled water

samples immersed in distilled water showed a strong tendency to weight reduction because of the degradation process.

All the HA ceramic samples analysed with the X-Ray method confirmed that hydroxyapatite is the only phase indicated in materials. Cristallization degree was independent of an immersion liquid and it was kept at similar level for all the materials.

The content of phosphorus in the samples after incubation in SBF and Ringer fluid was in the range of $18-19 \%$ and $18.90-19.23 \%$, respectively, whereas for hydroxyapatite samples immersed in distilled water it amounted to approximately $19 \%$. The phosphorus content was independent of the type of liquid and it increased in comparison with the content before in vitro tests.

The content of calcium was also independent of the kind of immersion fluid and amounted at average to $40 \%$ for all the samples. At the time of incubation calcium ions were resorbed from the hydroxyapatite surface into solutions and the quantity of calcium decreased.

\section{LITERATURE CITED}

1. Święcicki, Z. (1992). Bioceramics for orthopedics Instytut Podstawowych Problemów Techniki PAN, Wyd. Spółdzielcze Sp. z.o.o., Warszwa (in Polish).

2. Knychalska-Karwan, Z. \& Ślósarczyk, A. (1994). Hydroxyapatite in stomatology Krakmedia, Kraków (in Polish).

3. Ślósarczyk, A. (1997). Hydroxyapatite bioceramics Biuletyn Ceramiczny nr 13 Ceramika 51, Polskie Towarzystwo Ceramiczne, Kraków (in Polish).

4. Shin, H., Jo, S. \& Mikos, A.G. (2003). Biomimetic materials for tissue engineering. Biomaterials 24, 4353 - 4364.

5. Vallet-Regi, M. \& Gonzales-Calbert J. (2004). Calcium phosphates as substitution of bone tissues. Prog. Solid St. Chem. 32, 1 - 31. Received 1 December 2003; received in revised form 1 June 2004; accepted 15 July 2004, from Science Direct database on the World Wide Web: www.elsevier.nl/locate/pssc. DOI:10.1016/ j.progsolidstchem.2004.07.001.

6. Alpert, N.L., Kaiser, W.E. \& Szymański H.A. (1973). Infrared spectroscopy - theory \& practice PWN Warszawa (in Polish).

7. Rapacz-Kmita, A., Paluszkiewicz, C., Ślósarczyk, A. \& Paszkiewicz Z. (2005). FTIR and XRD investigations on the thermal stability of hydroxyapatite during hot pressing and pressure less sintering processes, J. Mol. Struc. 744 747, 653 - 656. Received 10 November 2004; accepted 30 November 2004 Available online 11 January 2005, from Science Direct database on the World Wide Web: www.elsevier.com/locate/molstruc. DOI:10.1016/ j.molstruc.2004.11.070.

8. Ślósarczyk, A., Paszkiewicz, Z. \& Paluszkiewicz C. (2005). FTIR and XRD evaluation of carbonated hydroxyapatite powders synthesized by wet methods, J. Mol. Struc $744-747$, 657 - 661. Received 10 November 2004; accepted 30 November 2004 Available online 11 January 2005, from Science Direct database on the World Wide Web: www.elsevier.com/ locate/molstruc. DOI: 10.1016/j.molstruc.2004.11.078. 